\title{
The Elderly Intestinal Microbiota: Opportunities for Probiotics
}

\section{Forssten SD ${ }^{1 *}$ and Ibrahim $\mathrm{F}^{2}$}

${ }^{1}$ Health \& Nutrition, Danisco Bioactives, Kantvik, Finland

${ }^{2}$ Functional Foods Forum, University of Turku, Turku, Finland

\begin{abstract}
The composition and activity of the intestinal microbiota appears to change upon ageing as a result of changes in gut physiology, diet, as well as immunological changes. The elucidation of the age-related changes in the composition of the intestinal microbiota is essential for finding proper dietary interventions for maintaining health and prophylaxis of diseases in elderly. Therefore, we reviewed the changes in the intestinal microbiota in elderly compared to adults and the potential use of probiotics to restore the microbial balance in elderly. Studies regarding the changes in the elderly microbiota compared to adults so far are limited and have showed inconsistent findings. The inconsistency could be attributed in part by the use of conventional culture techniques vs. molecular methods for the identification of fecal microbiota, but there still exists some inconsistency even within studies that applied only molecular methods. However, there is some evidence that a decrease in bifidobacterial diversity accompanied with an increase in bacteroides diversity is a consequence of old age. Although, there is still a great deal of research to be conducted to systematically uncover the changes of elderly microbiota and the factors driving this change, the research exploring the opportunities of probiotics in elderly disease is already ongoing, and the recent work in this area will be reviewed.
\end{abstract}

Keywords: Elderly; Microbiota; Probiotics; Bifidobacteria; Bacteroides

\section{Introduction}

Demographic studies have shown that an increasing fraction of human population will be over 65 years of age, and EU has projected that the share of people aged $\geq 65 \mathrm{y}$ in the total population will increase from $17 \%$ to $30 \%$ in 2060 . Likewise, the number of people aged $\geq 80 \mathrm{y}$ is estimated to almost triple from 21.8 million in 2008 to 61.4 million in 2060. There is also a constant increase in the percentage of the elderly population globally with different rates in various communities [1]. Although seniors can remain healthy for a large part of their life, ageing unavoidably leads sooner or later to a reduced performance of various physiological functions. Commonly suggested interventions to combat the deleterious effects of ageing are specific vaccination against viral disease, administration of anti-inflammatory and immunostimulatory drugs, nutrition interventions, and exercise. Pre- and probiotic have been introduced as potential tools to restore the immune functions in the elderly [2]. Probiotics provide an opportunity to modulate the functionality of the intestinal microbiota for the health benefit of the host. Therefore, this review will focus on age-related changes in the intestinal microbiota and the potential use of probiotics to restore the microbial balance in elderly.

\section{Functional intestinal microbiota}

The gastrointestinal tract serves as one of the biggest interfaces for interaction between the host and the external environment, and it has a complex community of microbes that vastly outnumber the host cells [3]. Over 1000 species can be identified within the intestinal microbiota [4] and the colonic population may attain levels as high as $10^{12} / \mathrm{g}$ [5].

Although people without a gut microbiota can survive [6], a functional intestinal microbiota affects immunological and pathological processes and hence the health of the host is influenced. The microbiota is responsible for functions such as fermentation of undigested substrates, preventing growth or colonization of harmful species and training the immune system. In addition, syntheses of some vitamins and hormone production are also mediated by the microbiota [7]. The knowledge and understanding of the composition of the intestinal microbiota is still limited but growing with the evolvement of molecular, culture-independent techniques [8].

\section{Intestinal microbiota in elderly}

In elderly, the composition of the intestinal microbiota was considered to be relatively stable [9], but it is now known that the composition changes with decreased species diversity and possibly reduced levels of beneficial bacteria $[10,11]$. A human individual will to some extent have a fixed microbiota, but changes in nutrient availability along the gastrointestinal tract are reflected in regional differences in bacterial concentrations and community. The individuality of the host has the largest impact on the composition of the microbial community $[11,12]$, but it is also affected by physiological, dietary, and environmental factors. For instance, changes in the intestinal mobility and nutrients availability occurring with age will have an impact in the composition of the intestinal microbiota. A decreased degree of mobility together with small bowel motor pattern changes in elderly may influence the motility of the bowel, having a negative effect on digestion, causing constipation, and may hence alter the gut microbiota. In addition, psychosocial stress factors may also contribute to changes in the immune system that may affect the composition of the gut microbiota in elderly [13]. Korshunov and colleagues compared the diversity and the amount of intestinal microbiota in three age groups (25-36, 55-68, 88-94 yrs) living in Switzerland, and it was observed that the highest values of both diversity and the total microbial count occurred in the group aged 55-68 yrs, and the microbiota of the advanced aged group

*Corresponding author: Forssten SD, Sokeritehtaantie 20, FI-02460 Kantvik, Finland, Tel: +35405367810; E-mail: sofia.forssten@danisco.com

Received July 29, 2011; Accepted October 18, 2011; Published October 22 2011

Citation: Forssten SD, Ibrahim F (2011) The Elderly Intestinal Microbiota: Opportunities for Probiotics. J Microbial Biochem Technol S1:002. doi:10.4172/1948-5948.S1-002

Copyright: (c) 2011 Forssten SD, et al. This is an open-access article distributed under the terms of the Creative Commons Attribution License, which permits unrestricted use, distribution, and reproduction in any medium, provided the original author and source are credited 
was the least diverse and had lowest total count [14]. These findings seem to be in agreement with that of Hopkin and colleagues [15] where lower viable counts of total anaerobes, bifidobacteria, BacteroidesPorphyromonas-Prevotella, and lactobacilli were observed in healthy elderly compared to young adults (67-88 vs 21-34 y). In addition, the elderly group harbored higher viable count of Enterobacteriaceae and clostridia. The same studies included a sub-group of geriatric patients (68-73 y) with Clostridium difficile-associated diarrhea, and the abovementioned alterations in the intestinal microbiota was much more pronounced indicating that age itself may not have much influence, but the disease status may be the main inducer of commonly observed microbial shift. Close results were also reported by the same authors [16] where bacteroides species diversity increase in the faeces of elderly individuals, and bifidobacterial species diversity dramatically decreases with age.

The anaerobes Bifidobacteria, Bacteroides, Clostridium, Eubacterium, and Ruminococcus represent the dominant species in an adult intestinal microbiota. Bifidobacteria are considered as beneficial colonic species, and the bifidobacterial genus in adults may contain up to five different species. In elderly, a reduction of bifidobacterial species diversity occurs and one or two dominant organisms are present. It has been shown that Bifidobacterium adolescentis or the phenotypically similar B. angulatum, B. bifidum and B. longum are the dominant species [17-19] in elderly. The decrease in bifidobacterial species diversity may be due to reduced adhesion capacity to the intestinal mucosa though it is not clear if this is due to microbial changes or physiochemical changes in the structure of colonic mucosa [20,21]. A decreasing tendency of bifidobacteria counts were reported by culture based studies where bifidobacteria have been isolated from $50-80 \%$ of stool samples. Meanwhile, studies based on molecular techniques have identified bifidobacteria from $100 \%$ of the faecal samples from elderly groups [12,22]. A decrease in the Bacteroides species diversity with an increasing age was reported $[12,18]$, but Bacteroides thetaiotaomicron were found in all individuals [23]. However, the levels of Bacteroides, Enterococci, Enterobacteriaceae and Clostridium were not different from adults while an increase of Lactobacillus and Enterococci was detected in a study by Mitsouka [24]. Higher quantities of Ruminococcus but lower quantities of Eubacterium and Bacteroides were found in elderly when compared to younger adults [20]. In contrast, higher level of enterobacteria was observed in the microbiota of elderly than among the microbiota of adults $[25,26]$.

The Clostridium genus consists of a heterogeneous assemblage species with highly diverse nutritional requirements and habitats. In elderly, clostridia have been found to be prevalent in significantly higher numbers compared to younger subjects. Clostridium cluster IV has been showed to dominate in elderly [11], and C. difficile is frequently isolated from elderly, particularly at long-term-care facilities [27]. On the other hand, it was shown that levels of Clostridium cluster XIVa seems to decrease in elderly compared to younger persons [28]. Ljungberg and co-authors detected higher number of clostridia in feces from elderly subjects than young adults no matter whether or not were taken a ciprofloxacin regimen [29].

An increased diversity of eubacteria was reported in elderly population [16], and some members of the Eubacterium genus that are phylogenetically related to the clostridia were also found to increase with age [30]. Hopkins and coauthors [31] reported lower levels of Bifidobacterium and Lactobacillus in elderly subjects as compared to healthy adults. Some lactobacilli species like Lactobacillus gasseri,
Lactobacillus reuteri, and Lactobacillus ruminis may be present as indigenous species all the time while the alterations of levels of others species within the Lactobacillus genus may originate from food derived transient species, erroneously indicating an altered microbiota. This is not surprising as the consumption of probiotics at a daily dose of $10^{9}$ $10^{10} \mathrm{CFU}$ evidently affect the composition and activity of the intestinal microbiota. Therefore, dietary intakes should be carefully controlled to obtain valid results. The diversity and the total counts of microbiota were compared among two elderly groups averaged 68 and 84 y group in a study by Benno and coauthors [10]. They found the total anaerobic bacteria, Clostridium, and Bacteroides, and the isolation rate of Bacillus subtilis to be lower in $84 \mathrm{y}$ than $68 \mathrm{y}$, but bifidobacteria and fusobacteria were higher in the $84 \mathrm{y}$ than $68 \mathrm{y}$. The findings of this study could be noticeably confounded by fiber intake.

Analysis of human microbiota of fecal samples from ten individuals (five young and five elderly adults) using a phylogenetic microarray, the human intestinal tract chip (HITChip), revealed contrasting results with the other studies with different methodologies either conventional or molecular methods [32]. The marked differences are that members of actinobacteria and bacilli were highly abundant in elderly compared to young while members of clostridium and bacteroides were highly abundant in adults. A more recent study with the same methodology found that the microbial composition and diversity of the gut ecosystem of young adults and seventy-year old people is highly similar but they differ significantly from that of the centenarians [33]. In a study with 230 healthy subjects at four European locations (France, Germany, Italy, and Sweden) categorized into two age groups (20 $50 \mathrm{y}$ and $>60 \mathrm{y}$ ), the fecal microbiota was analyzed using a set of 14 group- and species-specific $16 \mathrm{~S}$ rRNA-targeted oligonucleotide probes by fluorescence in situ hybridization coupled with flow cytometry [34]. Marked age-related differences in the microbiota composition were observed, but the result cannot be generalized as the differences were not independent of the location [34]. For example the group identified as Bacteroides-Prevotella ( $\mathrm{Bac} 303$ ) was significantly higher in elderly compared to adults in Germany but the opposite was true in Sweden and Italy. Similar age-regional comparison conducted in China using reference strains for target groups and 16S rRNA real-time PCR primers showed similar findings to the European study regarding the age-region interactions [35] as independent age or regional effects did not contribute to the observed changes.

Enck and colleagues analyzed fecal flora by conventional microbiological methods using stool samples from a very large number of subjects (35-292) expanding wide range of age (18 to 96 y) from young adult to elderly in advanced age [36]. Based on the results from this study, the total bacterial counts can be considered constant with no age-related differences. However, some species increased with age (E. coli and Enterococci spp.), others decreased with age (Bacteroides spp.), and others stay stable throughout life (lactobacilli, bifidobacteria). In another study [37] where GPCR was used to assess of human fecal microbiota from three age-groups (infants, adults and the elderly), the most pronounced difference was that a dramatic reduction in the ratio of Firmicutes to Bacteroidetes from 10.9 in adults to 0.6 in elderly. Similar results were reported in other studies [38].

The age-related alterations in the composition of the gut microbiota will also be translated into changes in the metabolic activity which in turn has various consequences on the health of the host. The gut microbiota can positively contribute to the intestinal epithelial cell differentiation and proliferation through the production of short- 
Citation: Forssten SD, Ibrahim F (2011) The Elderly Intestinal Microbiota: Opportunities for Probiotics. J Microbial Biochem Technol S1:002. doi:10.4172/1948-5948.S1-002

Page 3 of 4

chain fatty acids (SCFA). A decrease in the SCFA production with an increasing age is primarily associated with antibiotic treatment [30], but it is also associated with a decline in the levels of butyrate-producing bacteria, such as Eubacterium and Faecalibacteria [39]. On the other hand, fusobacteria ferment amino acids, resulting in production of several harmful end-products such as indoles and ammonia [40]. Similar activities are reported for Propionibacterium acnes, and an increase of these bacteria has been reported in elderly populations $[18,30,31]$ leading to unfavorable putrefactive microbial metabolism [26]. The microbial activity in the colon may also be influenced by an increased transit time in elderly as prolonged transit time reduces the availability of nutrients, shifting the balance towards putrefaction. This shift was observed in a study where the activities of nine enzymes and the concentrations of 11 metabolites in fecal samples from 21 elderly persons (69 to $89 \mathrm{y}$ ), 15 adults (30-46 y), and 14 children (3$15 \mathrm{y})$, the enzyme activities were not significantly different between groups, nor the major carbohydrate fermentation metabolites, e.g., acetate, propionate, butyrate, and L-lactate [41]. However, the elderly had higher D/L lactate ratio and higher concentrations of protein fermentation metabolites (ammonia, valerate, iso-butyrate and isovalerate).

\section{Opportunities for probiotics}

The age-related changes in the composition and activity of the intestinal microbiota seem to correlate with a greater vulnerability to inflammatory and viral disease, and, therefore, restoring the intestinal balance may have a significant health impact on the elderly population. Probiotic intervention is a potential tool for attaining such balance. Although the alteration in the elderly microbiota still not fully elucidated, several studies aimed at the use of specific probiotic strains in elderly disease prevention and/or treatment have already been conducted in various countries, and the main findings will be presented. Specific probiotic strains have been shown to exert beneficial effects or health improvements on elderly such as modulation of immune system functions and composition of the gut microbiota, as wells as the different aspects of gut health and function. In respect to the changes in the intestinal microbiota, a number of strains have been shown to increase the faecal levels of endogenous bifidobacteria and/ or lactobacilli [42]. This does not necessarily equal to a clinical health benefit, but may serve as a marker for improved gut environment.

Recently, various elderly populations have been targeted for interventions with different probiotics strains, strain combinations, or symbiotic preparations $[2,43]$. Two studies showed that specific probiotic strains might reduce the risk of catching common cold or influenza in elderly $[44,45]$ whereas in another study the rate of infection was not affected but the duration of respiratory tract infection and rhinopharyngitis was shortened [46]. The consumption of Lactobacillus casei DN-114 001 for elderly population (76 yrs) has lead to the reduction in both the episode and the cumulative duration of respiratory tract infections and rhinopharyngitis but it did not affect the severity, fever, pathogen's occurrence, nor some immune blood parameters [46]. The consumption of this strain had also lead to a change in the intestinal microbiota as the level of L. casei species in the stools increased during the time of the consumption. Another study showed that the same strain, $L$. casei DN-114001, did reduced the duration of the infection but not the incidence of winter infection [47]. A mixture of Lactobacillus rhamnosus and Propionibacterium freudenreichii increased the defecation frequency in elderly population but it did not reduce the laxative use [48].

\begin{tabular}{|l|l|c|}
\hline Strain & Immune markers & References \\
\hline Bifidobacterium longum BB536 & $\begin{array}{l}\text { Influenza vaccine antibody } \\
\text { titre, NK cells and bactericidal } \\
\text { activity of neutrophils }\end{array}$ & {$[45]$} \\
\hline Bifidobacterium lactis HN019 & $\begin{array}{l}\text { Phagocytic activity, NK } \\
\text { cells, relative proportions of } \\
\text { leukocyte subsets }\end{array}$ & {$[49]$} \\
\hline Bifidobacterium lactis Bb-12 & TNF-alpha and IL-10. & {$[19]$} \\
\hline Lactobacillus. rhamnosus HN001 & NK cells and phagocytic activity & 50] \\
\hline Lactobacillus johnsonii La1 & $\begin{array}{l}\text { Percentage of days with } \\
\text { infections, TNF-alph, } \\
\text { phagocytic activity }\end{array}$ & {$[51$} \\
\hline Lactobacillus casei DN-114 001 & $\begin{array}{l}\text { Resistance to common } \\
\text { infectious disease, influenza- } \\
\text { vaccine antibody titre }\end{array}$ & {$[46,52]$} \\
\hline
\end{tabular}

Table 1: Commercial probiotics shown to enhance immune system in elderly.

Various immune markers have showed improvement by the intake of probiotics by in elderly (Table 1). Additionally, a study by Schiffrin and others showed that the intake of probiotics might help in reducing the low-grade chronic inflammation in elderly [53].

A few studies have directly addressed the effect of probiotic intakes on the composition of the intestinal microbiota. In some studies, institutionalized elderly ( $\mathrm{n}=17,78-94 \mathrm{y}$ ) had less diversity of total bacterial diversity and bifidobacteria than the young adults $(\mathrm{n}=17$, 18-31 y) but higher numbers of Bacteroides cells [54]. It was possible to modify the intestinal microbiota even by the intake of a single strain, B. lactis HN019, in a dose range from $6.5 \times 10^{7}$ to $5 \times 10^{9} \mathrm{CFU} /$ day. This lead to an increase of the number of resident Bifidobacteria, Lactobacilli, Enterocci, but reduced the Enterobacteria counts [55]. However, synbiotics (prebiotic and probiotic) might be more effective in changing the microbiota composition, affecting in particular Bifidobacteria [56].

\section{Conclusions}

Studies regarding the changes in the elderly microbiota compared to adults so far are limited and have showed inconsistent findings. The inconsistency could be attributed to different methodology, approach, setting, and individual variations. However, there is some evidence that a decrease in bifidobacterial diversity accompanied with an increase in bacteroides diversity is a consequence of old age. Several studies indicated that the use of probiotics bacteria hold promise in the prevention of some elderly disease, but the use of probiotic should be more focused on restoring the alterations in original composition of the intestinal microbiota. Therefore, it is important to improve our knowledge of the age-related changes in the composition and activity of the intestinal microbiota before probiotics interventions strategies can be accurately recommended as prophylaxis for elderly diseases.

\section{References}

1. World Population Prospects (2008) Population Division of the Department of Economic and Social Affairs of the United Nations Secretariat, World Population Prospects: The 2008 Revision, http://esa.un.org/unpp, Wednesday, June 24, 2009.

2. Candore G, Balistreri C, Colonna-Romano, G, Grimaldi M, Lio D, et al. (2008) Immunosenescence and Anti-Immunosenescence Therapies: The Case of Probiotics. Rejuvenation Res 11: 425-432.

3. Savage D (1977) Microbial Ecology of the Gastrointestinal Tract. Annu Rev Microbiol 31: 107-133.

4. NIH HMP working group. Human Microbiome Project (HMP). 2010; Available from: http://nihroadmap.nih.gov/hmp/pressreleases.asp. 
Citation: Forssten SD, Ibrahim F (2011) The Elderly Intestinal Microbiota: Opportunities for Probiotics. J Microbial Biochem Technol S1:002. doi:10.4172/1948-5948.S1-002

5. Zoetendal E, Vaughan E, de Vos W (2006) A microbial world within us. Mol Microbiol 59: 1639-1650.

6. Steinhoff $U$ (2005) Who controls the crowd? New findings and old questions about the intestinal microflora. Immunol Lett 99: 12-16.

7. Guarner F, Malagelada J (2003) Gut flora in health and disease. The Lancet 361: 512-519.

8. Blaut M, Collins M, Welling G, Dor J, Loo J, et al. (2002) Molecular biological methods for studying the gut microbiota: the EU human gut flora project $\mathrm{Br}$ Nutr 87: S203-S211.

9. Mitsuoka T (1992) Intestinal flora and aging. Nutr Rev 50: 438-446.

10. Benno Y, Endo K, Mizutani T, Namba Y, Komori T, et al. (1989) Comparison of fecal microflora of elderly persons in rural and urban areas of Japan. Appl Environ Microbiol 55: 1100-1105.

11. Claesson M, Cusack S, O'Sullivan O, Greene-Diniz R, de Weerd H, et al. (2011) Composition, variability, and temporal stability of the intestinal microbiota of the elderly. PNAS 108: 4586-4591

12. Bartosch S, Fite A, Macfarlane G, McMurdo M (2004) Characterization of Bacterial Communities in Feces from Healthy Elderly Volunteers and Hospitalized Elderly Patients by Using Real-Time PCR and Effects of Antibiotic Treatment on the Fecal Microbiota. Appl Environ Microbiol 70: 3575-3581.

13. Holdeman L, Good I, Moore W (1976) Human fecal flora: variation in bacteria composition within individuals and a possible effect of emotional stress. Appl Environ Microbiol 31: 359-375.

14. Korshunov V, Potashnik L, Efimov B, Korshunova O, Smeianov V, et al. (2001) Qualitative composition of the normal intestinal microflora in individuals from the various age groups. Zh Mikrobiol Epidemiol Immunobiol 2: 57-61.

15. Hopkins M, Sharp R, Macfarlane G (2001) Age and disease related changes in intestinal bacterial popular-ions assessed by cell culture, $16 \mathrm{~S}$ rRNA abundance, and community cellular fatty acid profiles. Gut 48: 198-205.

16. Hopkins M, Macfarlane G (2002) Changes in predominant bacterial populations in human faeces with age and with Clostridium difficile infection. J Med Microbiol 51: $448-454$

17. Gavini F, Cayuela C, Antoine J, Lecoq C, Lefebvre B, et al. (2001) Differences in the Distribution of Bifidobacterial and Enterobacterial Species in Human Faecal Microflora of Three Different (Children, Adults, Elderly) Age Groups. Microb Ecol Health Dis 13: 40-45.

18. Hopkins M, Sharp R, Macfarlane G (2002) Variation in human intestinal microbiota with age. Dig Liver Dis 34: S12-S18.

19. Ouwehand A, Bergsma N, Parhiala R, Lahtinen S, Gueimonde M, et al. (2008) Bifidobacterium microbiota and parameters of immune function in elderly subjects. FEMS Immunol Med Microbiol 53: 18-25.

20. He F, Ouwehand A, Isolauri E, Hosoda M, Benno Y, et al. (2001) Differences in Composition and Mucosal Adhesion of Bifidobacteria Isolated from Healthy Adults and Healthy Seniors. Curr Microbiol 43: 351-354.

21. Ouwehand A, Isolauri E, Kirjavainen P, Salminen S (1999) Adhesion of four Bifidobacterium strains to human intestinal mucus from subjects in different age groups. FEMS Microbiol Lett 172: 61-64.

22. Reuter G (2001) The Lactobacillus and Bifidobacterium Microflora of the Human Intestine: Composition and Succession. Curr Issues Intest Microbiol 2: 43-53.

23. Layton A, McKay L, Williams D, Garrett V, Gentry R, et al. (2006) Development of Bacteroides 16S rRNA Gene TaqMan-Based Real-Time PCR Assays for Estimation of Total Human, and Bovine Fecal Pollution in Water. Appl Environ Microbiol 72: 4214-4224.

24. Mitsuoka T (1996) Intestinal flora and human health. Asia Pacific J Clin Nutr 5 2-9.

25. Guigoz Y, Doré J, Schiffrin E (2008) The inflammatory status of old age can be nurtured from the intestinal environment. Curr Opin Clin Nutr Metab Care 11: $13-20$

26. Tiihonen K, Tynkkynen S, Ouwehand A, Ahlroos T, Rautonen N (2008) The effect of ageing with and without non-steroidal anti-inflammatory drugs on gastrointestinal microbiology and immunology. Br J Nutr 100: 130-137.
27. Simor A, Bradley S, Strausbaugh L, Crossley K, Nicolle L (2002) Clostridium difficile in long-term-care facilities for the elderly. Infect Control Hosp Epidemio 23: 696-703.

28. Hayashi H, Sakamoto M, Kitahara M, Benno Y (2003) Molecular Analysis of Fecal Microbiota in Elderly Individuals Using $16 S$ rDNA Library and T-RFLP. Microbiol Immunol 47: 557-570.

29. Ljungberg B, Nilsson-Ehle I, Edlund C, Nord C (1990) Influence of ciprofloxacin on the colonic microflora in young and elderly volunteers: no impact of the altered drug absorption. Scand J Infect Dis 22: 205-208.

30. Woodmansey E, McMurdo M, Macfarlane G, Macfarlane S (2004) Comparison of Compositions and Metabolic Activities of Fecal Microbiotas in Young Adults and in Antibiotic-Treated and Non-Antibiotic-Treated Elderly Subjects. App Environ Microbiol 70: 6113-6122.

31. Hopkins M, Sharp R, Macfarlane G (2001) Age and disease related changes in intestinal bacterial populations assessed by cell culture, 16S rRNA abundance and community cellular fatty acid profiles. Gut 48: 198-205.

32. Rajilic-Stojanovic M, Heilig H, Molenaar D, Kajander K, Surakka A, et al. (2009) Development and application of the human intestinal tract chip, a phylogenetic microarray: analysis of universally conserved phylotypes in the abundant microbiota of young and elderly adults. Environ Microbiol 11: 1736-1751.

33. Biagi E, Nylund L, Candela M, Ostan R, Bucci L, et al. (2010) Through Ageing, and Beyond: Gut Microbiota and Inflammatory Status in Seniors and Centenarians. Plos One 5: e10667.

34. Mueller S, Saunier K, Hanisch C, Norin E, Alm L, et al. (2006) Differences in Fecal Microbiota in Different European Study Populations in Relation to Age, Gender, and Country: a Cross-Sectional Study. Appl Environ Microbiol 72 1027-1033.

35. Zhao L, Xu W, Ibrahim S, Jin J, Feng J, et al. (2011) Effects of age and region on fecal microflora in elderly subjects living in Bama, Guangxi, China. Cur Microbiol 62: 64-70.

36. Enck P, Zimmermann K, Rusch K, Schwiertz A, Klosterhalfen S, et al. (2009) The Effects of Ageing on the Colonic Bacterial Microflora in Adults. Zeitschrift Fur Gastroenterologie 47: 653-658.

37. Mariat D, Firmesse O, Levenez F, Guimaraes V, Sokol H, et al. (2009) The Firmicutes/Bacteroidetes ratio of the human microbiota changes with age. BMC Microbiol 9: 123

38. Makivuokko H, Tiihonen K, Tynkkynen S, Paulin L, Rautonen N (2010) The effect of age and non-steroidal anti-inflammatory drugs on human intestinal microbiota composition. Br J Nutr 103: 227-234.

39. Pryde S, Duncan S, Hold G, Stewart C, Flint H (2002) The microbiology of butyrate formation in the human colon. FEMS Microbiol Lett 217: 133-139.

40. Woodmansey E (2007) Intestinal bacteria and ageing. J Appl Microbiol 102 1178-1186.

41. Andrieux C, Membre J, Cayuela C, Antoine J (2002) Metabolic characteristics of the faecal microflora in humans from three age groups. Scand J Gastroent 37: 792-798.

42. Gopal P, Prasad J, Gill H (2003) Effects of the consumption of Bifidobacterium lactis HN019 (DR10 (TM)) and galacto-oligosaccharides on the microflora of the gastrointestinal tract in human subjects Nutr Res 23: 1313-1328.

43. Nova E, Warnberg J, Gomez-Martinez S, Diaz L, Romeo J, et al. (2007) Immunomodulatory effects of probiotics in different stages of life. $\mathrm{Br} \mathrm{J}$ Nutr 98 S90-95.

44. Makino S, Ikegami S, Kume A, Horiuchi H, Sasaki H, et al. (2010) Reducing the risk of infection in the elderly by dietary intake of yoghurt fermented with Lactobacillus delbrueckii ssp. bulgaricus OLL1073R-1. Br J Nutr 104: 9981006.

45. Namba K, Hatano M, Yaeshima T, Takase M, Suzuki K (2010) Effects of Bifidobacterium longum BB536 administration on influenza infection, influenza vaccine antibody titer, and cell-mediated immunity in the elderly. Biosci Biotechnol Biochem 74: 939-945

46. Guillemard E, Tondu F, Lacoin F, Schrezenmeir J (2010) Consumption of a fermented dairy product containing the probiotic Lactobacillus casei DN-114001 
Citation: Forssten SD, Ibrahim F (2011) The Elderly Intestinal Microbiota: Opportunities for Probiotics. J Microbial Biochem Technol S1:002. doi:10.4172/1948-5948.S1-002

Page 5 of 4

reduces the duration of respiratory infections in the elderly in a randomised controlled trial. Br J Nutr 103: 58-68.

47. Turchet $P$, Laurenzano M, Auboiron S, Antoine J (2003) Effect of fermented milk containing the probiotic Lactobacillus casei DN-114001 on winter infections in free-living elderly subjects: a randomised, controlled pilot study. J Nutr Health Aging 7: 75-77

48. Ouwehand A, Lagstrom H, Suomalainen T, Salminen S (2002) Effect of probiotics on constipation, fecal azoreductase activity and fecal mucin content in the elderly. Ann Nutr Metab 46: 159-162.

49. Fukushima $\mathrm{Y}$, Miyaguchi $\mathrm{S}$, Yamano $\mathrm{T}$, Kaburagi $\mathrm{T}$, lino $\mathrm{H}$, et al. (2007) Improvement of nutritional status and incidence of infection in hospitalised, enterally fed elderly by feeding of fermented milk containing probiotic Lactobacillus johnsonii La1 (NCC533). Br J Nutr 98: 969-977.

50. Ibrahim F, Ruvio S, Granlund L, Salminen S, Viitanen M, et al. (2010) Probiotics and immunosenescence: cheese as a carrier. Fems Immunol Medical Microbiol 59: $53-59$.

51. Gill H, Rutherfurd K, Cross M, Gopal P (2001) Enhancement of immunity in the elderly by dietary supplementation with the probiotic Bifidobacterium lactis HN019. American J Clin Nutri 74: 833-839.
52. Boge T, Remigy M, Vaudaine S, Tanguy J, Bourdet-Sicard R, et al. (2009) A probiotic fermented dairy drink improves antibody response to influenza vaccination in the elderly in two randomised controlled trials. Vaccine 27: 5677 5684

53. Schiffrin E, Parlesak A, Bode C, Bode J, van't Hof M, et al. (2009) Probiotic yogurt in the elderly with intestinal bacterial overgrowth: endotoxaemia and innate immune functions. Br J Nutr 101: 961-966.

54. Zwielehner J, Liszt K, Handschur M, Lassl C, Lapin A, et al. (2009) Combined $P C R-D G G E$ fingerprinting and quantitative-PCR indicates shifts in fecal population sizes and diversity of Bacteroides, bifidobacteria and Clostridium cluster IV in institutionalized elderly. Experiment Gerontol 44: 440-446.

55. Ahmed M, Prasad J, Gill H, Stevenson L, Gopal P (2007) Impact of consumption of different levels of Bifidobacterium lactis HN019 on the intestinal microflora of elderly human subjects. J Nutr Health Aging 11: 26-31.

56. Bartosch S, Woodmansey E, Paterson J, McMurdo M, Macfarlane G (2005) Microbiological effects of consuming a synbiotic containing Bifidobacterium bifidum, Bifidobacterium lactis, and oligofructose in elderly persons, determined by real-time polymerase chain reaction and counting of viable bacteria Clin Infect Dis 40: 28-37.
This article was originally published in a special issue, Probiotics handled by Editor(s). Dr. Arunachalam Muthaiyan, University of Arkansas, USA 